\title{
Leibniz: liberdade e verdade
}

\author{
Tessa Moura Lacerda \\ tessalacerda@gmail.com \\ Universidade de São Paulo, São Paulo, Brasil
}

resumo Não há, para Leibniz, separação entre uma esfera ética, na qual seriam consideradas as ações voluntárias dos homens e sua busca pelo bem, e uma esfera epistemológica, pela qual se explicaria a busca pela verdade. Partindo aqui deste pressuposto, procuramos mostrar, primeiro, em que sentido se pode dizer que o conhecimento é uma ação voluntária; e, segundo, como a ação moral só é verdadeiramente livre se fundamentada no conhecimento do verdadeiro. Por isso o modelo de homem livre é o homem sábio.

palavras-chave Leibniz; substância; expressão; liberdade; sábio; verdade

\section{A substância em Leibniz: unidade e ação}

Leibniz define a verdade, em um opúsculo escrito por volta de 1686, nos seguintes termos:

Verdadeira é a proposição cujo predicado está contido no sujeito ou, de maneira mais geral, cujo consequente está contido no antecedente, e por isso é necessário que exista uma certa conexão entre as noções dos termos ou que haja na coisa mesma um fundamento a partir do qual se possa dar a razão da proposição ou se possa estabelecer uma demonstração a priori. E se exige que em toda proposição verdadeira afirmativa universal ou singular, necessária ou contingente, a noção do predicado esteja compreendida na noção do sujeito, expressa ou virtualmente, expressamente na proposição idêntica, virtualmente em qualquer outra (LEIBNIZ 1903/1961, p.401-402).

Recebido em 19 de dezembro de 2013. Aceito em 20 de julho de 2014.

doispontos, Curitiba, São Carlos, vol. 11, n. 2, p.209-229, outubro, 2014 
Essa definição é exemplar da concepção analítica da verdade em Leibniz e, eventualmente com alguma mudança nas palavras, comparece em vários de seus textos. O que define a verdade é a inclusão do predicado ou consequente no sujeito ou antecedente; inclusão que pode ser expressa e explícita, no caso das verdades idênticas, ou virtual, nas verdades não idênticas; inclusão que pode ser demonstrada facilmente por meio da análise lógica em uma proposição necessária (seja pela análise exclusiva do sujeito, seja pela análise e comparação dos dois termos, o sujeito e o predicado), ou que exigiria uma análise infinita no caso das verdades contingentes que envolvem a liberdade divina e a conexão de cada elemento do universo criado com todos os demais do conjunto.

É essa definição da verdade que fundamenta em grande medida a doutrina leibniziana da substância individual. Se a verdade de uma proposição se define pela inclusão expressa ou virtual do predicado no sujeito, a substância define-se, no Discurso de metafísica de 1686, como uma noção completa, um sujeito de todos os seus predicados, sem diferenciação entre predicados essenciais e acidentais; isso porque, para Leibniz, "toda predicação tem algum fundamento na natureza das coisas" (Leibniz, 2004a, $\$ 8$ p.16), e atribuir um predicado ao sujeito significa mostrar como efetivamente aquele predicado está incluído na natureza daquele sujeito e como, em conexão com todos os demais predicados daquele sujeito, contribui para definir o indivíduo como um sujeito singular, único:

a natureza de uma substância individual ou de um ser completo consiste em ter uma noção tão perfeita que seja suficiente para compreender e fazer deduzir de si todos os predicados do sujeito a que se atribui esta noção (Leibniz, 2004a, \$8, p.16-17).

Essa concepção do indivíduo como aquele que possui uma noção completa de todos os seus predicados impõe à primeira vista limites à afirmação da liberdade moral de escolha, pois "como a noção individual de cada pessoa encerra de uma vez por todas quanto lhe acontecerá, nela se vêem as provas a priori da verdade de cada acontecimento ou a razão de ter ocorrido um de preferência a outro" (LEIBNIIZ, 2004a, \$13, p.25). Ora, em que sentido se pode atribuir responsabilidade moral a uma criatura cujas ações já podiam ser previstas desde toda eternidade? Mais do que previstas, as ações do indivíduo estão predeterminadas por sua noção 
completa. Se não houver propriamente escolha moral, se não se puder afirmar categoricamente o livre arbítrio, como pensar a responsabilidade moral em um mundo em que, segundo Leibniz, não deveria haver boas ações sem recompensa nem más ações sem castigo, recompensa e castigo que fazem a essência de uma república (cf. LEIBNIZ, 2004a, \$36)?

Leibniz previu essa objeção e nem a intensa troca de cartas com Arnauld - troca iniciada com o envio do sumário do Discurso de metafísica em 1686 e mantida até 1690 -, nem a força da crítica do teólogo nas primeiras dessas cartas o fizeram mudar de opinião. Com efeito, o restante do enunciado do artigo citado acima veicula que: "estas verdades, porém, embora asseguradas, não deixam de ser contingentes, pois fundamentam-se no livre-arbítrio de Deus ou das criaturas, cuja escolha tem sempre suas razões, inclinando sem necessitar” (LEIBNIZ, 2004a, \$13, p.25). Embora esteja contido na noção individual de cada pessoa não apenas o que lhe aconteceu e está acontecendo, mas tudo o que lhe acontecerá, isto é, embora haja uma predeterminação do futuro, a conexão entre o sujeito e o predicado não é uma conexão necessária. Há, no sujeito, razões que explicam cada evento vivido por ele, cada decisão tomada, mas, em primeiro lugar, somente a Deus cabe conhecer a totalidade infinita dessas razões, porque como dirá Leibniz anos mais tarde na Monadologia, "há uma infinidade de figuras e de movimentos presentes e passados que entram na causa eficiente desse meu ato presente (...), e há uma infinidade de pequenas inclinações e disposições de minha alma, presentes e passadas, que entram na sua causa final." (LEIBNIZ 2004b, \$36, p.137); e, em segundo lugar, essas razões não tornam o oposto do que acontece impossível em si mesmo ou contraditório, mas apenas incompossível com este mundo criado. $\mathrm{O}$ que não acontece e jamais vai acontecer no nosso mundo não é em si mesmo uma impossibilidade, mas algo incompatível com este conjunto de coisas, com esta série de acontecimentos. E porque permanecem essencialmente contingentes, esses eventos possíveis são o que Leibniz considera em sua Teodiceia a base para a admissão da liberdade. Com efeito, nesse texto, um ato livre é definido a partir de três características: a contingência da ação, que exclui a necessidade lógica, é a base da liberdade; a espontaneidade do agente, o corpo; e a inteligência, ou o conhecimento do objeto da deliberação, é a alma da liberdade (cf. LEIBNIZ, $1969, \$ 288$ p.290). 
A definição da liberdade de ação como espontaneidade permite mostrar como, em lugar de ser incompatível com a afirmação da liberdade da criatura e, portanto, com a responsabilidade moral, a noção completa da substância é o que garante que essa liberdade seja efetiva. Sem uma noção completa, o sujeito de ação não poderia ser dito verdadeiramente um agente espontâneo. Uma vez que tudo o que acontece a cada um encontra sua razão na própria noção do sujeito, então esse sujeito é sempre espontâneo, o correlato da espontaneidade do sujeito é a noção completa que o define.

Mas o que dá alma à liberdade é a capacidade humana de refletir sobre o objeto de deliberação. Essa capacidade transforma um ato contingente e espontâneo em um ato moral e diferencia as criaturas inteligentes de todas as demais (cf. LACERDA, 2002). Um leão é um agente espontâneo, mas jamais poderá ser acusado pelo assassinato de uma zebra porque é incapaz de refletir sobre sua própria ação. É essa capacidade que nos torna seres morais. A liberdade para Leibniz não está no poder de escolha entre contrários - em certo sentido, isso caracteriza qualquer ação espontânea, já que tudo o que se passa no mundo criado é contingente e o que não acontece permanece logicamente possível, mas o que é logicamente possível nem sempre é moralmente possível. A liberdade para Leibniz não está na indiferença - já que a razão contida em cada substância individual inclina o indivíduo a sua ação, essa razão está baseada na natureza do indivíduo ou na noção do sujeito (cf. LEIBNIZ, 2003, p.400).A liberdade está na capacidade do agente de refletir sobre sua própria existência e sobre sua ação com consciência de si mesmo, mesmo que haja quem jamais se utilize dessa capacidade e siga atordoado pela vida. Externamente a ação é idêntica: um sinal de trânsito vermelho leva a maior parte dos motoristas a parar o carro, mas uns param para evitar multa de trânsito, outros - e estou sendo otimista - param porque compreendem que sua ação faz parte de um conjunto e a harmonia do conjunto depende em parte dessa ação. A liberdade se define como determinação contingente e inteligente.

*

A concepção leibniziana da verdade como a inclusão do predicado no sujeito explica a definição da substância como noção completa e 
consequentemente é importante para a afirmação da liberdade, mas a rigor não define inteiramente o que é a substância individual para Leibniz. A autonomia que deve caracterizar uma ação livre não pode ser explicada apenas pela noção completa que faz da substância a causa única de tudo o que lhe acontece, essa autonomia explica-se também pela capacidade de ação. Sem essa capacidade de agir, a substância não poderia realizar ou desenvolver no tempo sua noção completa. A substância é essencialmente ativa, e a ação é pensada em analogia com a força física.

A doutrina leibniziana da substância é constituída a partir da confluência de reflexões trazidas da lógica, da matemática, da teologia e da fisica. A substância é, antes de tudo e seguramente, um sujeito lógico de predicados. Mas esse sujeito é constituído por infinitos predicados, como na matemática a unidade pode ser pensada a partir da soma de infinitos elementos que se encadeiam segundo uma lei própria. A substância finita define-se como uma série infinita de fenômenos (cf. BRUNSCHVICG, 1912, p.171-177, p.197-249). A noção de substância individual é uma noção completa, na qual está contida a totalidade da série infinita de acidentes que definem essa substância, seu passado, seu presente e seu futuro. Esse sujeito de infinitos predicados é pensado em analogia com a alma e, precisamente, com a alma humana que dá identidade ao indivíduo ao longo de sua existência. Para Leibniz "é tudo como aqui em toda parte e sempre” (LEIBNIZ, 1875-85,VI, p.546), o que está afastado, explica-se perfeitamente pelo que está perto, pelo que conhecemos, por isso, diz o filósofo numa carta a Arnauld (LEIBNIZ, 1966, Carta 9/10/1687, p.188), não sabemos o que são as outras substâncias, conhecemo-nos a nós mesmos pela reflexão e pela nossa capacidade de reconhecer este "eu" que nos define; mas supomos que as demais formas sejam análogas a nossa alma e a esse eu. Mesmo que concebamos uma hierarquia de substâncias e que as almas racionais, na medida em que têm essa capacidade de reconhecer-se como autoras de suas ações presentes, passadas e futuras, sejam superiores àquelas almas que não são dotadas da capacidade de reflexão, ainda assim, estas são pensadas em analogia com nossa alma. E essa alma que é una, idêntica a si mesma, é um princípio de ação. Leibniz repete em inúmeros textos: "actiones sunt suppositorum", as ações pertencem propriamente às substâncias, e essa atividade, essa ação, é pensada a partir da noção dinâmica de força. 
A noção de substância que proponho, noção tão fecunda que dela se seguem as verdades primeiras (...). (...) direi por ora que a noção de força, ou seja, potência (que os alemães chamam de Kraft e os franceses de force) - para cuja explicação dediquei a ciência especial da Dinâmica - traz muitíssima luz para entender a verdadeira noção de substância.

(LEIBNIZ, 1875-85, IV, p.469, trad. p.457)

É esse conceito fisico que permitirá a Leibniz pensar a substância individual como princípio de ação, com a autonomia que esse princípio implica, e caracterizar a substância não apenas pela sua unidade de sujeito de uma série infinita de predicados, mas também pela ação.

Essa ação caracteriza toda e qualquer substância criada e permite que Leibniz se mantenha fiel à definição cartesiana de substância - "uma coisa que existe de tal maneira que só tem necessidade de si própria para existir" (DESCARTES, 1997, I, 51, p.45) - sem correr o risco de fazer de Deus a única causa efetiva no mundo, a única substância, como sustenta Espinosa. Quando a substância que age é uma substância racional sua ação é sempre pensada como ação livre - ainda que sejamos "meramente empíricos em três quartos de nossas ações” (LEIBNIZ, 2004b, \$28 p.136) e atuemos segundo apenas o princípio da memória, sem pensar na causa das coisas, exatamente como os animais. A ação de uma criatura racional é sempre dita livre, porque a razão nos abre a um mundo novo, o conhecimento das verdades necessárias e eternas, que partilhamos com Deus e

pelo conhecimento das verdades necessárias e por suas abstrações, elevamo-nos aos atos reflexivos, (...); e é assim que, ao pensar em nós, pensamos no ser, na substância, no simples ou no composto, no imaterial e no próprio Deus (...) (LEIBNIZ, 2004b, \$30, p.136).

Isso significa que, por um lado, o homem é por sua própria natureza de ser racional um ser moral: a consciência de si e o reconhecimento de suas ações como suas transformam suas escolhas, que são ações espontâneas, em ações morais; mas, por outro lado, como é o conhecimento das verdades eternas e necessárias que nos eleva aos atos reflexivos, o conhecimento da verdade revela-se como uma tarefa ética. Se a razão leva os homens a ingressarem naturalmente em uma espécie de sociedade com Deus, um reino moral da graça no seio do mundo natural, cabe a esses homens se 
fazerem verdadeiros colaboradores de Deus. A alma humana, que é arquitetônica nas ações voluntárias e imita Deus, alma que é capaz de conhecer o sistema do universo e seu criador, deve pôr seu conhecimento a serviço de Deus e criar em seu pequeno mundo o que observa no grande.

Vê-se assim que, para Leibniz, liberdade e verdade formam um par inseparável: só é verdadeiramente livre aquele que age de acordo com o conhecimento da verdade.

\section{A liberdade de pensar a verdade}

A expressão, a relação regrada e constante entre o que se pode dizer do exprimido e o que se pode dizer da expressão, é comum a todas as formas, "é um gênero do qual a percepção natural, o sentimento animal e o conhecimento intelectual são as espécies." (LEIBNIZ, 1966, carta 9/10/1687, p.181). Na percepção natural e no sentimento animal, o que é material e está disperso em vários seres é representado ou exprimido em um único ser indivisível. Trata-se da percepção. No conhecimento intelectual, essa representação ou expressão pode ser acompanhada de consciência, "e é então que é chamada de pensamento" (LEIBNIZ, 1966, carta 9/10/1687, p.181). Os seres racionais são capazes de apercepção e é precisamente isso que os diferencia dos demais.

Mas sabemos também que

experimentamos em nós mesmos um estado no qual não nos lembramos

de nada, nem temos nenhuma percepção distinta, como quando

sofremos um desmaio ou somos vencidos por um profundo sono sem sonhos. Neste estado, a alma não difere sensivelmente de uma simples Mônada (LEIBNIZ, 2004b, \$20, p.134).

Neste estado de atordoamento temos apenas uma percepção natural. Mas quando voltamos do aturdimento, apercebemo-nos de nossas percepções, esse estado em que não se pode distinguir nada não é duradouro, a alma subtrai-se dele, "ela é algo mais" (Idem. ibidem).

Além disso,

Os homens agem como os animais quando as consecuções de suas

percepções só se efetuam pelo princípio da memória (...); e somos 
meramente empíricos em três quartos de nossas ações. Por exemplo, quando se espera que amanhã raie o dia, procede-se como um empirista, porque sempre foi assim até hoje. Só o astrônomo julga, nesse caso, segundo a razão. (LEIBNIZ, 2004b, $\$ 28$, p.136).

Na maior parte de nossa existência, em três quartos de nossas ações, diz Leibniz, temos apenas sentimentos animais.

Se a percepção natural, o sentimento animal e o conhecimento intelectual são espécies dentro de um mesmo gênero, é porque são graus do mesmo, graus de distinção perceptiva: do aturdimento do completamente obscuro à consciência reflexiva de si mesmo que leva ao conhecimento de verdades eternas. Essas espécies de expressão estão presentes nas diferentes espécies de seres da natureza, mas estão também todas reunidas em um único ser, aquele entre as criaturas que alcança o grau mais elevado de expressão, o homem, e é por isso que essas expressões podem ser ditas todas graus do mesmo - o homem é a prova dessa afirmação.

Todas as mônadas são espelhos vivos que representam ou exprimem o universo segundo seu ponto de vista, mas a alma racional "não é só um espelho do universo das criaturas como também uma imagem da divindade" (LEIBNIZ, 2004c, \$14, p.161), não apenas percebe o universo, a obra de Deus, como descobre as ciências segundo as quais Deus regulou as coisas e "imita em seu âmbito e em seu pequeno mundo (...) o que Deus faz no grande" (LEIBNIZ, 2004c, \$14, p.161). Os espíritos são mais perfeitos, diz Leibniz no Discurso de metafísica, exprimem incomparavelmente melhor o Criador que as outras substâncias, porque exprimem com o conhecimento daquilo que fazem, e portanto, podem conhecer verdades acerca de Deus e do universo. Eis por que o filósofo pode dizer que "a diferença entre as substâncias inteligentes e as que não o são é tão grande como a que há entre o espelho e aquele que vê" (LEIBNIZ, 2004a, \$35, p.74-75).

É o conhecimento das verdades eternas que faz com que esse grau no interior da percepção, que é a razão, crie uma distância entre os homens e os animais, por um lado, e aproxime mais o homem de Deus, por outro. Como Deus na criação, o homem estabelece nas matemáticas, por exemplo, teoremas a partir de algumas suposições, extraindo o máximo de resultados de um mínimo de hipóteses, cria conhecimentos nos quais 
é indubitável "a conexão entre as ideias e infalíveis suas conseqüências" (LEIBNIZ, 2004c, \$5, p.156). Se Deus cria como "um excelente geômetra, que sabe encontrar as melhores construções de um problema” (LEIBNIZ, 2004a, \$5, p.10), o geômetra, completa Serres (SERRES, 1968, p.135), pensa como Deus cria. Nossa alma é arquitetônica, ao descobrir "as ciências segundo as quais Deus regulou as coisas (pondere, mesura, numero etc.)" (LEIBNIZ, 2004c, \$14, p.161) imita o arquiteto divino, que “arranja o lugar e o alicerce, destinados ao edifício, da maneira mais vantajosa, nada deixando destoante ou destituído de toda a beleza de que é suscetível" (LEIBNIZ, 2004a, \$5, p.10). Somos imagem de Deus, exprimimos Deus em cada uma de nossas ações, mas é pelo conhecimento - Leibniz fala nas "ações voluntárias" - que essa imagem se aproxima mais de seu modelo. Nesse caso não há separação entre uma esfera ética, na qual seriam consideradas as ações voluntárias dos homens e sua busca pelo bem, e uma esfera epistemológica, pela qual se explicaria a busca pela verdade. $\mathrm{O}$ conhecimento é fruto de uma ação voluntária tanto quanto a criação do mundo - e o bem e a verdade são um único fim.

O conhecimento é fruto de uma ação voluntária porque exige atenção, memória, reflexão, exige um esforço para tornar presente à consciência o que é inerente à essência, para trazer à tona ideias inatas mas não pensadas. Não é dado ao homem compreender o infinito, embora possa pensá-lo; assim, nesse processo de desenvolvimento do envolvido está implicada necessariamente uma "escolha". Há uma multiplicidade a ser atualizada, pensada. Se cada substância individual exprime o universo de um ponto de vista determinado, há partes desse mundo que são percebidas com maior clareza que outras. Se o olhar de cada sujeito individual for pensado como uma fonte de luz, a área iluminada por esse olhar luzente é a zona clara desse sujeito, é o que esse sujeito transforma em ideia, é o que o sujeito escolhe.

Ora, em que sentido a escolha que define o conhecimento pode ser dita uma escolha voluntária se nossos pensamentos nascem uns dos outros por uma necessidade hipotética? Em que sentido há escolha se a perspectiva de nosso olhar sobre o mundo, que determina nossa zona clara de percepção, é constitutiva de nossa essência enquanto indivíduos (ver, por exemplo, LEIBNIZ 1969, \$124, p.181)? Afinal, na medida em que nossos pensamentos nascem uns dos outros por uma necessidade 
hipotética e em correspondência com tudo o que se passa com nosso corpo, que por sua vez está em correspondência com tudo o que se passa no mundo, porque não há vazio no universo, tudo é pleno, nessa medida, pensamos o que pensamos, no momento em que pensamos, também por uma necessidade hipotética (cf. LEIBNIZ 1966, Carta 28 nov 1686; LEIBNIZ, 2004b, §61, p.142).

Se pensamos o que pensamos em correspondência com tudo o que se passa no universo, também as ideias claras, ou aquelas que, no interior de uma multiplicidade infinita, são escolhidas para serem pensadas por seu grau de determinação, têm esse grau de maneira necessária, de acordo com nosso ponto de vista, e por isso são necessariamente "escolhidas".

Explicar as coisas desta maneira é atribuir ao mundo uma necessidade que Leibniz jamais atribuiu. É hipoteticamente necessário que eu pense no que estou pensando no momento em que penso, mas não é contraditório que eu pense em outra coisa, por isso não é absolutamente necessário que as ideias que se destacam por sua clareza da multiplicidade obscura da percepção sejam conhecidas. É por isso que Leibniz afirma que os sentidos são ocasiões ou dão a ocasião para o pensamento de ideias, não tornam esse pensamento um pensamento necessário. Nossos pensamentos nascem uns dos outros, segundo uma causalidade final, e correspondem aos movimentos de nosso corpo que nascem uns dos outros, segundo a causalidade eficiente. Mas como seríamos capazes de ciências demonstrativas se o curso de nossos pensamentos seguisse uma necessidade tão estrita?

Para responder essas questões é preciso, primeiro, retomar a importância que o conhecimento das verdades eternas tem para os homens e, segundo, estabelecer a diferença entre ideia e noção.

Ainda que haja uma tal necessidade no curso de nossos pensamentos, escapamos dessa "coação" pelo conhecimento das verdades necessárias e eternas. O conhecimento das verdades eternas, cuja ocasião é dada por aquele primeiro momento de reflexão da alma ou de apercepção, é um conhecimento independente dos sentidos e, por isso, independente do paralelismo entre corpo e alma. Isso quer dizer que podemos escolher pensar nas verdades eternas e construir conhecimentos a partir delas, como o conhecimento demonstrativo das matemáticas, sem que haja uma solicitação dos sentidos para que façamos isso. Podemos dizer que nossas percepções seguem a necessidade hipotética explicada pela correspondência 
expressiva entre alma e corpo, mas não nosso conhecimento. É o que Leibniz indica ao distinguir, nos Novos ensaios ${ }^{1}$, ideias e pensamentos: os pensamentos correspondem ao que chamamos impressões perceptivas e, nesse sentido, correspondem sempre a alguma sensação, mas as ideias, os objetos do que chamamos conhecimento, existem sempre em nós, independentes dos sentidos, são inatas. Uma vez que são inatas, os sentidos serão apenas uma ocasião para o pensamento de ideias, para o conhecimento, que não se submete, portanto, à necessidade hipotética que comanda o nascimento de um pensamento a partir de outro, todo o tempo, e a correspondência desses pensamentos com os movimentos do corpo. Daí Leibniz afirmar, nos Novos ensaios, que "se o corpo não está jamais em repouso, a alma que the corresponde tampouco existe sem percepção" (LEIBNIZ, 1990, II, i, \$10, p.89), seria contrário à natureza um estado da alma em que ela não pensasse, isso não é uma escolha; mas os juízos que fazemos a partir dessas percepções resultam de ações voluntárias, escolhas. Eis por que, embora nossas percepções sejam todas sempre verdadeiras, nossos juízos não o são. Como afirma o filósofo no Discurso de metafísica, cada substância criada corresponde a uma visão de Deus do conjunto geral dos fenômenos que formam o mundo, "e como a visão de Deus é sempre verdadeira, as nossas percepções igualmente o são, mas nossos juízos, que são apenas nossos, nos enganam” (LEIBNIZ, 2004a, \$14, p.29). Na Teodiceia Leibniz refina essa distinção entre percepção e juízo estabelecendo uma diferença entre os sentidos externos e um sentido interno. Quando vemos ao longe uma torre retangular, a enxergamos como se fosse arredondada, porque "a representação dos sentidos, mesmo quando eles fazem tudo o que depende deles, é frequentemente contrária à verdade" (LEIBNIZ, 1969, “Discours" \$64, p.88). Ora, mas então onde está a verdade de nossa percepção que corresponde a uma visão de Deus sobre o universo? "Os sentidos externos, para falar propriamente, não nos enganam. É nosso sentido interno que muitas vezes nos faz ir rápido demais; (...) ele se engana pelo julgamento que faz dos efeitos das aparências, e infere mais do que elas supõem” (LEIBNIZ, 1969, "Discours" \$65, p.88). Em resumo, é preciso estabelecer uma distinção, primeiro, entre impressão sensível e expressão em ideia, pensamento e ideia, e, segundo, no interior da percepção, uma distinção entre os sentidos externos e o sentido interno, o juízo. Dessa maneira, nossas percepções ou pensamentos, que correspondem a 
sensações, nascem umas das outras por uma necessidade hipotética e segundo uma causalidade final. Se essas percepções nos enganam, é porque julgamos rápido demais a respeito do que percebemos, então não são as percepções sensíveis que nos enganam, mas nosso sentido interno.

$\mathrm{Na}$ medida em que distinguimos, nos pensamentos, o que provém dos sentidos externos (em linguagem metafisica, o que corresponde a sensações) e o que depende de nosso sentido interno ou juízo, podemos distinguir também os pensamentos ou percepções e o conhecimento, cujo objeto são as ideias, independentes dos sentidos. Da mesma maneira que, numa percepção, quando temos o tempo de nos recolher e raciocinar com vagar, podemos julgar que a torre vista à distância, embora aparentemente arredondada, é retangular, no conhecimento podemos nos dedicar à análise de uma ideia que tenha vindo à consciência por ocasião de uma solicitação dos sentidos, embora em nada dependa deles. Mesmo que essa ideia tenha vindo à consciência no momento preciso em que veio, o conhecimento não segue a necessidade do pensamento. Não somos passivos no conhecimento. $\mathrm{Na}$ verdade, não há passividade absoluta na substância - mesmo que haja paixão ${ }^{2}$. Ao contrário, o conhecimento exige esforço. O conhecimento é fruto de uma ação e implica atenção e memória.

Há uma infinidade de impressões em cada percepção, somos incapazes de compreender essa infinidade, nós dirigimos nossa atenção e, ao fazer isso, pensamos em ideias que nos são inatas. Pensar em uma ideia é desprender algo que se exprime de uma multiplicidade de impressões, e analisar, na medida de nossa possibilidade, essa expressão, dar uma forma à percepção. É claro que ao dirigir nossa atenção a alguma coisa, alguma ideia inata, deixamos de prestar atenção a outras que poderiam vir à tona por ocasião de alguma solicitação dos sentidos. Trata-se de uma escolha. Mas, além disso, como o que constitui nossa personalidade é a memória que guardamos de tudo o que vivemos e de tudo o que conhecemos ${ }^{3}$, a cada novo conhecimento, temos a possibilidade de mobilizar nossos conhecimentos anteriores. Aliás, mobilizamos esse conhecimento expressamente ou não, mas para construir uma ciência, fazemos isso com consciência.

Podemos dizer que somos um espelho vivo, um centro expressivo da totalidade do universo, percebemos tudo, mas confusamente, no momento em que nos aplicamos a nossas percepções com atenção e memória, somos pequenos deuses, não apenas um espelho, mas aquele que vê a 
imagem, e ao fazer isso, esclarece a confusão. Mesmo que jamais lancemos luz sobre toda a confusão de nossas percepções, esclarecemos progressivamente o mundo que exprimimos, pelo uso da razão. Quando Leibniz afirma, na Teodiceia, que há uma mistura de pensamentos confusos em nossos pensamentos distintos, quer dizer que não podemos analisar nossas percepções até o fim, porque se trata de uma análise infinita, e por isso todo pensamento distinto traz consigo a confusão como companheira, porque exprime a totalidade do universo. Nos Princípios da natureza e da graça, Leibniz afirma que "cada percepção distinta da alma compreende uma infinidade de percepções confusas que envolvem todo o universo (...). Cada alma conhece o infinito, conhece tudo, mas confusamente" (LEIBNIZ, 2004c, \$13, p.160). Na verdade deveríamos dizer que, na medida em que a alma conhece o infinito confusamente, não conhece propriamente, mas percebe, pensa de maneira infinita, "a própria alma só conhece as coisas que pode perceber na medida em que possui percepções distintas e acuradas destas coisas” (LEIBNIZ, 2004c, \$13, p.160). Leibniz afirma que "a alma é um pequeno mundo, no qual as ideias distintas são uma representação de Deus e as confusas são uma representação do universo" (LEIBNIZ, 1990, II, i, \$1, p.87). As impressões produzidas pelo mundo em nós são percepções confusas, e dão origem a ideias confusas. Na medida em que temos alguma percepção distinta e acurada, essa percepção pode ser a ocasião para o conhecimento de uma ideia, mas essa ideia só será uma ideia distinta se exprimir uma ideia de Deus, se passarmos da impressão à expressão. No conhecimento, só conseguimos sair de uma análise infinita exigida por cada impressão perceptiva se encontrarmos a razão suficiente do mundo. É por isso que nossas ideias distintas são representações de Deus, nossas ideias são distintas quando exprimem ideias divinas, quando exprimem, por suas relações, relações presentes nas ideias de Deus. Porque assim representam a razão da multiplicidade presente em cada percepção. As ideias que representam o universo, na medida em que o conhecimento de verdades de fato envolve uma análise infinita e nós não compreendemos esse infinito, são sempre ideias confusas.

Mas se, nas verdades de fato ou contingentes, há sempre uma mistura de percepções confusas e percepções distintas, Leibniz não diz nunca que não conhecemos verdades idênticas ou cuja análise pode levar a uma identidade como no caso das verdades eternas e necessárias. A confusão 
nos define como criaturas, mas não constrange nosso conhecimento, nem nos priva de conhecimentos que apresentam consequências infalíveis e uma conexão indubitável entre ideias. Os sentidos devem ser pensados como uma "ajuda" para o desenvolvimento de ideias envolvidas, como uma ocasião para a atualização de virtualidades, e não como tiranos que nos obrigam a pensar no que pensamos.

É para pensar os sentidos como essa "ajuda" que Leibniz distingue, no Discurso de metafísica, as ideias e as noções: as expressões que estão em nossa alma, quer concebamos ou não, são ideias; aquelas que formamos ou concebemos, são noções ou conceitos. Seria preciso acrescentar que podemos imaginar que estamos formando uma noção, quando na verdade estamos usando palavras vãs ou falando de quimeras - trata-se das ideias falsas, que sugerem uma crítica da linguagem, sobretudo à linguagem dos escolásticos ${ }^{4}$. As noções são, portanto, as ideias inatas que se atualizam por uma atenção que a alma dedica a si mesma quando a ocasião, em linguagem prática ${ }^{5}$, a solicitação dos sentidos, se apresenta.

Podemos dizer que há três níveis expressivos nas substâncias inteligentes: primeiro a expressão "passiva" da totalidade do universo em cada alma; depois a expressão ativa no esforço da alma de se desenvolver, no ser e no conhecer, esforço que leva ao conhecimento das ideias inatas; e, por fim, a expressão do universo e de Deus no saber positivo produzido pelos homens. Os três níveis estão intimamente ligados: entre o primeiro e o segundo nível há identidade na medida em que a totalidade confusa passivamente exprimida é o objeto sobre o qual a ação expressiva de conhecer se exerce. Mas no segundo nível vemos a relação direta entre a liberdade e a verdade, do ponto de vista do conhecimento: o conhecimento pode ser dito em certa medida uma ação voluntária. O terceiro nível, por sua vez, envolve a relação entre liberdade e verdade do ponto de vista da ação moral propriamente dita, na medida em que o saber positivo produzido pelo homem permite que este reproduza em seu pequeno mundo o que descobre no grande.

\section{0 sábio: conhecimento da verdade e amor 6}

Acima mostramos como conhecer é uma ação voluntária (quase como a criação do mundo): o bem e a verdade são um único fim, porque o 
desenvolvimento de uma atitude ética de busca pelo bem geral está necessariamente vinculado ao conhecimento, conhecimento do mundo como o melhor dos mundos, e de sua causa, um Deus soberanamente bom e sábio. Sem esse conhecimento, o homem não pode se compreender como parte de um todo harmônico e perceber que buscar o bem para si mesmo é necessariamente buscar o bem do todo. Sem o conhecimento, o homem é incapaz de ultrapassar a perspectiva egoísta e individualista que define sua busca essencial pelo bem, incapaz de ultrapassar o tradicional neminem laedere por meio da procuratio boni allieni.Vejamos.

Como a moral leibniziana foi deixada em estado de esboço, a tentativa de constituir uma moral não-normativa, que articule os desejos dos indivíduos, pode ter lugar de condição de possibilidade da ética. Leibniz tem como projeto uma enciclopédia que daria o perfeito conhecimento dos princípios de todas as ciências e a arte de aplicá-los; mas como não possuímos essa sabedoria e, ao mesmo tempo, na nossa ação prática não temos como fazer a análise de noções dos verdadeiros bens ligados à situação em que estamos - porque, finitos, não temos a compreensão da infinidade que caracteriza a contingência -, a pergunta pela conduta moral ideal permanece sem resposta. Por isso o papel do indivíduo que age, tateando em busca do que aparece como um bem de acordo com a tendência natural da vontade de buscar o bem, é fundamental para a moralidade. A moral se encarna, assim, no homem sábio (LEIBNIZ, 1982, p.402-403). Leibniz não opõe o desejo à razão (como não opõe natureza e liberdade), ele dá à razão a tarefa de nos esclarecer na busca pelo mais desejável: o sábio não age de acordo com uma legalidade exterior e transcendente, ele encontra uma retidão do desejo prevenindo os desvios de inclinações. O sábio harmoniza a razão e o desejo através da reflexão sobre o que leva à ação.

O desejo do homem mobiliza seu poder de agir em direção a um fim que ele, como criatura, persegue sem saber muito bem o que é: a realização de sua noção. $\mathrm{O}$ indivíduo moral precisa deliberar sobre o que deve ser escolhido e esclarecer pela razão o desejo para que ele busque o efetivamente melhor e não sua sombra. Essa passagem entre a espontaneidade da vontade em relação ao bem e uma ação refletida em que a razão reconhece o melhor ou, pelo menos, diminui o risco de erro, se dá através do direito. Os motivos que guiam uma ação justa e a eficácia dessa justiça são graduados de acordo com o objeto - que é refletido na formulação 


\section{4}

das leis através da subdivisão do direito em direito privado ou justiça comutativa (cujo objeto é o indivíduo ou a utilidade privada), direito público ou justiça distributiva (cujo objeto é a sociedade ou a utilidade comum restrita) e direito interno ou justiça universal (que visa a Deus ou a utilidade comum universal).

A divisão da justiça humana de acordo com o objeto do direito reproduz, em alguma medida, o desenvolvimento da sabedoria em um indivíduo. As normas devem expressar o que acontece com um homem sábio que, individualmente, passa do direito privado à equidade e, finalmente, à piedade. Em um primeiro momento, o indivíduo racional esclarece as leis que regem o melhor dos mundos e entende sua situação pelo conhecimento das razões que o levaram a existir. Assim reconhece, na sua individualidade, a racionalidade universal que está inscrita nele. Isso o leva a passar de uma inclinação espontânea para o bem próprio a uma inclinação ao bem comum; ele identifica seu movimento a um conjunto de movimentos que concordam entre si e, ao mesmo tempo em que se reconhece como autor de suas ações, adere ao conjunto: através do amor, vê a felicidade do outro como constitutiva da sua e pode se dirigir à busca do bem público. O que regula a inclinação é seu objeto, o outro, e que o homem identifica com a vontade de Deus, revelada pela religião. A transformação que se opera em um indivíduo que amplia sua percepção até adotar o outro no interior de si mesmo, leva essa criatura a dirigir sua vontade não mais somente para a vontade de Deus, mas para Deus mesmo. No fim desse percurso, o sábio não precisa mais das regras do direito, ele é o modelo para essas máximas.

Caridade do sábio: esta é a versão final da definição leibniziana de justiça. Noção arquitetônica que permitirá a Leibniz articular natureza e graça, direito e religião. Há duas formas de desejar o bem alheio (cf. LEIBNIZ, 1930, I, p.464): a primeira é desejá-lo como consequência do nosso próprio bem, a segunda, como nosso próprio bem. Como o bem alheio pode coincidir com nosso próprio bem e ser desejado por si mesmo?

A felicidade daqueles com cuja felicidade nos regozijamos se torna uma parte de nossa própria felicidade, porque as coisas que nos agradam são buscadas por elas mesmas. E como a contemplação mesma de coisas belas é agradável, e um quadro pintado por Rafael afeta aquele que o compreende, mesmo se não lhe traz nenhum proveito, a ponto de ser 
dominado nas delícias do olhar por alguma semelhança com o amor, da mesma forma, quando a coisa bela é ao mesmo tempo capaz também de felicidade, esse afeto se transforma em verdadeiro amor. (LEIBNIZ, 1992, p.162-163)

A possibilidade de sentir prazer no bem de outro é o fundamento da caridade, porque o prazer é um sentimento de perfeição, beleza e ordem. $\mathrm{O}$ amor puro e desinteressado é a fruição do prazer que a felicidade de um outro nos causa. A verdadeira virtude é desinteressada, agimos virtuosamente pelo prazer do bem.

Leibniz admite, todavia, que a maioria dos homens, ao realizar uma ação justa, não esquece a utilidade do ato. Para esses homens, fazer o bem a um outro é uma troca: praticam a virtude para que eles também recebam um bem.

Agir pela utilidade própria ou mesmo praticar um bem ao outro para garantir um bem para si mesmo expressa a fórmula que identifica a justiça à abstenção do mal. O que Leibniz pretende ao afirmar que o princípio de uma ação pode ser tanto a utilidade quanto o prazer e, mais que isso, pode ser os dois ao mesmo tempo, é mostrar primeiro que não há uma ruptura entre uma ação justa em sentido corrente e estreito (o neminem laedere hobbesiano) e em sentido próprio e mais amplo (procuratio boni allieni); e, segundo e principalmente, que pode haver uma continuidade entre desejar o bem alheio como consequência de nosso próprio bem e desejá-lo como nosso bem. Completando o dito - o que não queres que te façam ou o que queres que te façam, não faças ou não recuses aos outros -, Leibniz pretende diluir as fronteiras entre a disposição de não causar dano a um outro e a disposição de lhe fazer o bem, assim como entre a utilidade do bem e o prazer no bem.

A benevolência do sábio não é uma bondade ingênua, mas refletida apenas quem conhece profundamente pode ser bom, porque o desejo do bem deve estar unido a seu conhecimento, não há verdadeira liberdade sem conhecimento verdadeiro.

A justiça pode ser tomada de diferentes maneiras de acordo com o princípio que mova a ação justa (LEIBNIZ, 1994a, p.129-130): abstraindo Deus, a justiça é uma virtude particular. Tomada como abstenção do mal (neminem laedere), essa justiça particular será o princípio do direito privado 
ou justiça comutativa. Considerada como fazer o bem aos outros para garantir um bem a si mesmo (suum cuique tribuere), será princípio do direito público ou justiça distributiva. Na medida em que estiver fundada em Deus ou na imitação dele, a justiça será universal e conterá as demais virtudes, essa justiça universal é a piedade e por ela encontramos o bem próprio no bem geral e o mal geral em nosso mal, pois quando somos viciosos não lesamos apenas a nós mesmos, mas diminuímos, tanto quanto dependa de nossa ação, a perfeição da cidade de Deus. Em resumo, a justiça é particular ou universal. A justiça particular divide-se em comutativa (direito privado) e distributiva (direito público). A justiça universal é a piedade.

Como não há lei que possa obrigar quem quer que seja a sentir prazer na virtude (inversamente, quem sente amor pela virtude não tem necessidade de nenhuma lei para ser justo), as divisões da justiça propostas por Leibniz parecem sugerir dois caminhos para a implantação da justiça universal no mundo dos homens: um é estabelecer regras de direito que correspondam ao movimento da maioria dos homens (e, portanto, regras de fácil aceitação e adoção), isto é, do bem próprio ao bem coletivo e deste ao bem universal, ancorado na religião e no amor - ou temor - de Deus; o outro, um caminho mais longo e mais árduo, o esclarecimento dos homens, que os levaria progressivamente à sabedoria e, de posse dessa ciência da felicidade, os homens poderiam agir não mais pelo princípio da utilidade, mas pelo princípio do prazer.

O conhecimento racional leva à verdadeira liberdade, a liberdade do homem sábio, aquele que segue a lei por sua própria inclinação, porque se vê como membro do reino moral da graça que está instaurado no seio do mundo natural, e compreende-se como colaborador do Deus monarca, criador do melhor dos mundos possíveis.

1 “(..) creio que jamais existimos sem ideias, sem pensamentos e também sem sensações. Distingo apenas as ideias e os pensamentos; pois temos sempre todas as ideias puras ou distintas independente dos sentidos; mas os pensamentos correspondem sempre a alguma sensação." (LEIBNIZ, 1990, II, i, §23, p.94)

${ }^{2}$ A substância se define, vimos, pela ação e pela unidade. A ação da substância una pode ser identificada ao princípio interno que a faz passar de uma percepção para outra espontaneamente. A natureza da substância individual exige que ela seja expressiva da totalidade do

doispontos, Curitiba, São Carlos, vol. 11, n. 2, p.209-229, outubro, 2014 
universo. Não há ação de uma substância sobre outra, mas influência ideal. Assim, quando a causa de uma percepção não está na própria substância, porque todas se entreexprimem e toda mudança no universo toca a todas, dizemos que essa substância padece. Quando a substância exerce sua virtude ou exprime a totalidade como causa de uma mudança no universo, ela age. A paixão não significa, portanto, passividade em sentido estrito, mas uma mudança provocada pelo princípio interno da substância que não tem por causa ela mesma. Cf., por exemplo, LEIBNIZ 2004a, $\$ 15$.

${ }^{3}$ Leibniz afirma nos Novos ensaios que não é a lembrança (souvenir) que faz de um homem o mesmo homem, mas a perfeita ligação entre o futuro e o passado. A identidade do indivíduo não pode ser dada pela lembrança que ele tem do que já viveu, mas por essa ligação entre passado, presente e futuro, porque a lembrança não é necessária e nem sempre é possível, por conta da multiplicidade de impressões presentes e passadas que concorrem em nossos pensamentos presentes (LEIBNIZ 1990, II, i, \$12. Ed. cit. - p.88-89). Mas o sentido dessa afirmação é preciso: se dependêssemos das nossas lembranças para a garantia de nossa identidade, porque temos sempre percepções inapercebidas, passadas e presentes, aquilo de que não nos apercebemos ou o que esquecemos implicaria a constituição de uma nova identidade, de uma nova pessoa. Então, a identidade individual não é dada pela lembrança, mas pela ligação entre presente, passado e futuro, garantida pelas percepções insensíveis: "essas percepções insensíveis marcam ainda e constituem o mesmo indivíduo, que é caracterizado pelos vestígios que elas conservam dos estados precedentes deste indivíduo, estabelecendo a conexão com seu estado presente (...)" (LEIBNIZ 1990, "prefácio" - p.42). Por outro lado, no Discurso de metafisica, o filósofo afirma que o que constitui nossa personalidade, o que faz de uma substância individual uma pessoa, é a memória (sempre "souvenir") e o conhecimento de si, "pois é a recordação ou o conhecimento deste eu que a torna suscetivel de castigo e de recompensa” (LEIBNIZ 2004, \$34. Ed. cit. - p.72). Assim, a memória é essencial para a constituição de uma personalidade, mas a memória e o conhecimento de si, do eu que dá a identidade de todas as percepções, não a memória das próprias percepções, muitas esquecidas ou mesmo inapercebidas.

4 Sobre o tema, por exemplo, LEIBNIZ 1966, p.151 (Carta a Arnauld, 28/11/1686 $-8 / 12 / 1686$.$) .$

${ }^{5}$ Como Leibniz afirma na Monadologia, "somos meramente empíricos em três quartas partes de nossas ações”, quando não julgamos um evento segundo a razão e pelo conhecimento da causa que o explica. Assim, podemos dizer, em linguagem prática, que as idéias inatas se atualizam segundo a solicitação dos sentidos, embora a substância seja autônoma, espontânea e tenha em si mesma, ou em sua noção completa, a razão de tudo o que lhe acontece.

${ }^{6}$ Esta seção de nosso texto é profundamente inspirada no capítulo III de nosso livro $A$ política da metafísica. Teoria e prática em Leibniz (LACERDA, 2005).

\section{Referências bibliográficas}

BRUNSCHVICG, J. 1912. Les étapes de la philosophie mathématique, Paris: Alcan. 
DESCARTES, R. 1997. Princípios da filosofia. Lisboa: Edições 70.

LACERDA, T. M. 2002. “A liberdade de Leibniz", Cadernos de História e Filosofia da Ciência, Campinas, Série 3, v.12, p.171-186, jan-dez. 2002. 2005. A política da metafísica. Teoria e prática em Leibniz. São Paulo: Associação Editorial Humanitas.

LEIBNIZ, G. 1875-85. “Considérations” (1705). Philosophischen Schriften, VI. Herausgegeben von C. I. Gerhardt. Berlin, Weidmann, 7 vols. [reimpressões: Hildesheim/New York, Georg Olms, 1960-61; 1978. .1875-85a. "A reforma da filosofia primeira...” (1694), Philosophischen Schriften, IV. Herausgegeben von C. I. Gerhardt. Berlin, Weidmann, 7 vols. [Tradução argentina: Escritos filosóficos, Ed. E. de Olaso, Buenos Aires: Editorial Charcas, 1982].

.1930. "Elementa juris naturalis", Philosophische Schriften herausgegeben von der Preussischen Akademie der Wissenschaft, Darmstadt: Otto ReichlVerlag.

1966. Discours de métaphysique et correspondance avec Arnauld. Paris:Vrin. 1969. Essais de Theodicée, Paris: GF - Flammarion. .1982. "Da sabedoria" in Escritos Filosoficos (ed. de E. de Olaso): Buenos Aires, Editorial Charcas. 1990. Nouveaux essais sur l'entendemente humain. Paris: GF-Flammarion. . 1994. "Code diplomatique du droit des gens" in Le droit de la raison (texto réunis et présentés par R. Sève). Paris:Vrin. .1994a. "Méditation sur la notion commune de justice" in Le droit de la raison. (texto réunis et présentés par $\mathrm{R}$. Sève). Paris:Vrin. .19031961. "Sobre a natureza da verdade", in Couturat Opuscules et fragments inédits de Leibniz. ParisHildesheim. .2004a. Discurso de metafísica, São Paulo: Martins Fontes. 
2004b. Os princípios da filosofia ou a Monadologia, São

Paulo, Martins Fontes.

.2004c. Princípios da natureza e da graça, São Paulo: Martins

Fontes.

SERRES, M. 1968. Le système de Leibniz et ses modeles

mathématiques. Paris: PUF, volume I.

doispontos, Curitiba, São Carlos, vol. 11, n. 2, p.209-229, outubro, 2014 